Images in...

\title{
Multiple intracystic floating balls: an unusual but unique sonographic pattern of mature cystic teratoma
}

\author{
Anupama Tandon, ${ }^{1}$ Rachna Agarwal, ${ }^{2}$ Rajesh Tandon, ${ }^{3}$ Meenaklshi Prakash ${ }^{1}$ \\ 1Department of Radiology \& Imaging, UCMS \& GTB Hospital, New Delhi, India; \\ 2Department of Obstretics \& Gynecology, UCMS \& GTB Hospital, New Delhi, India; \\ ${ }^{3}$ Department of Histopathology, Max Hospital, New Delhi, India \\ Correspondence to Rajesh Tandon, rajesh.tandon@hotmail.com
}

\section{DESCRIPTION}

Mature cystic teratoma is the most common benign ovarian neoplasm occurring in the reproductive age group. ${ }^{1}$ Sonography is invariably the primary modality for diagnosis. The great diversity in components of teratomas results in varied sonographic appearances. Certain features like tip-of-iceberg sign, fat-fluid level, dermoid mesh and rokitansky protuberance (dermoid plug) are specific to this entity and considered diagnostic. ${ }^{2}$ A sonographic appearance of multiple free-floating spherical balls in a cyst as seen in the presented case is rare ${ }^{2}$ and may present a diagnostic difficulty to the unwary.

Transabdominal sonography in a 23-year-old patient complaining of lower abdominal discomfort revealed a $12 \times 8 \mathrm{cms}$ cystic mass in the lower abdomen. The cyst had a striking ultrasound appearance with multiple distinct, round $1-2 \mathrm{~cm}$ sized echogenic globules floating in it (figure 1). CT scan demonstrated a thin-walled cyst with hypodense floating balls within (figure 2). At laprotomy, a unilocular right ovarian cyst containing serous fluid and numerous small cheese-like sebum balls was found (figure 3). Histopathology confirmed the diagnosis of mature cystic teratoma; spherules contained desquamated keratin, fibrin, hemosiderin and sebaceous debris with skin squams and fine hair shafts and only a small amount of fat component.

The mechanism of formation of these globules is unclear till date. It is postulated that globules are formed by aggregation of sebaceous material around a nidus while moving in the cyst resulting in concentric layers of sebaceous material. The lower specific gravity than cyst contents accounts for their mobility. ${ }^{3}$

Sonography is diagnostic and further workup is unlikely to show any additional features. To the best of

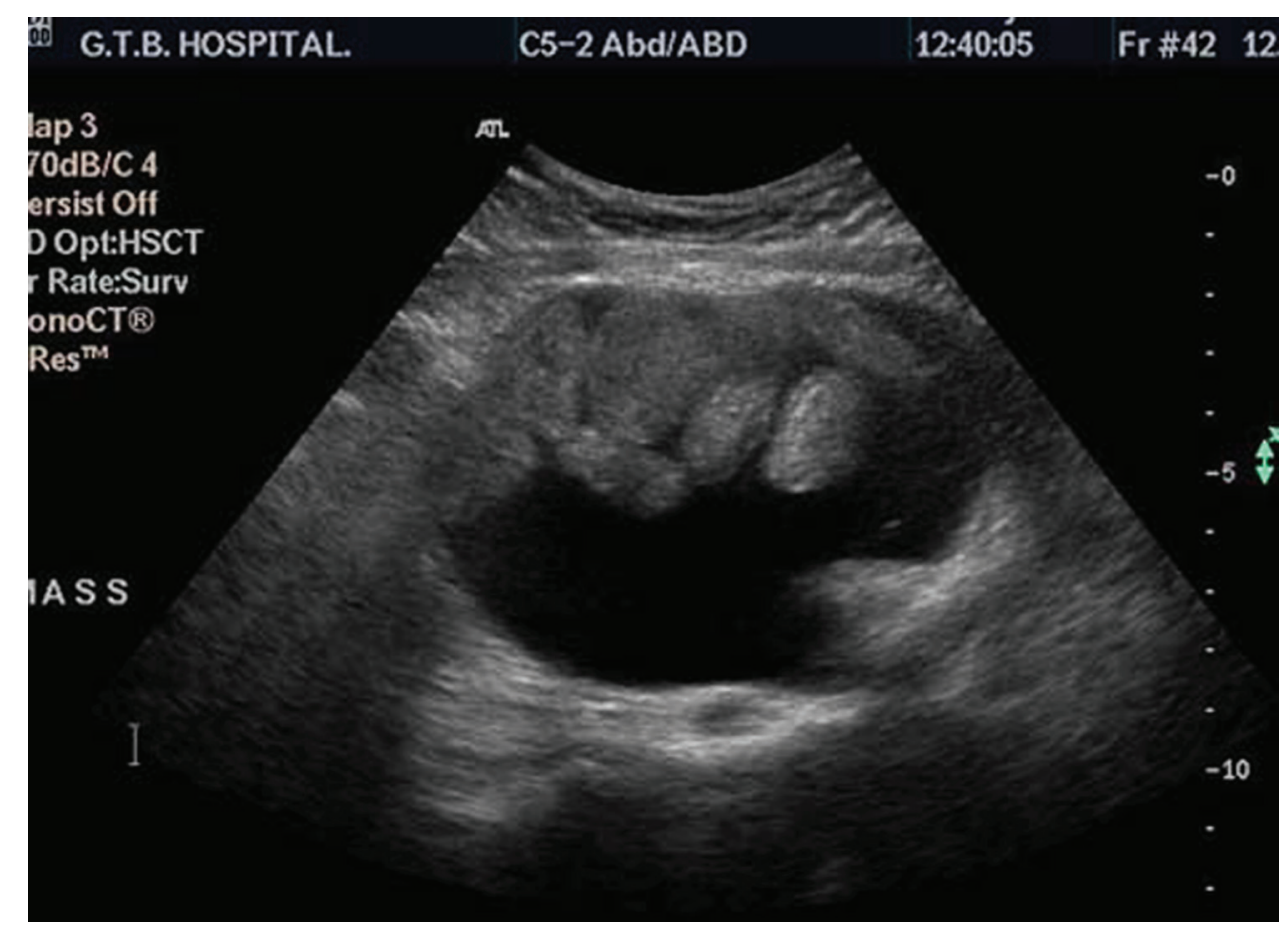

Figure 1 Sonogram showing multiple echogenic floating spherules in a cyst. 


\section{BMJ Case Reports}

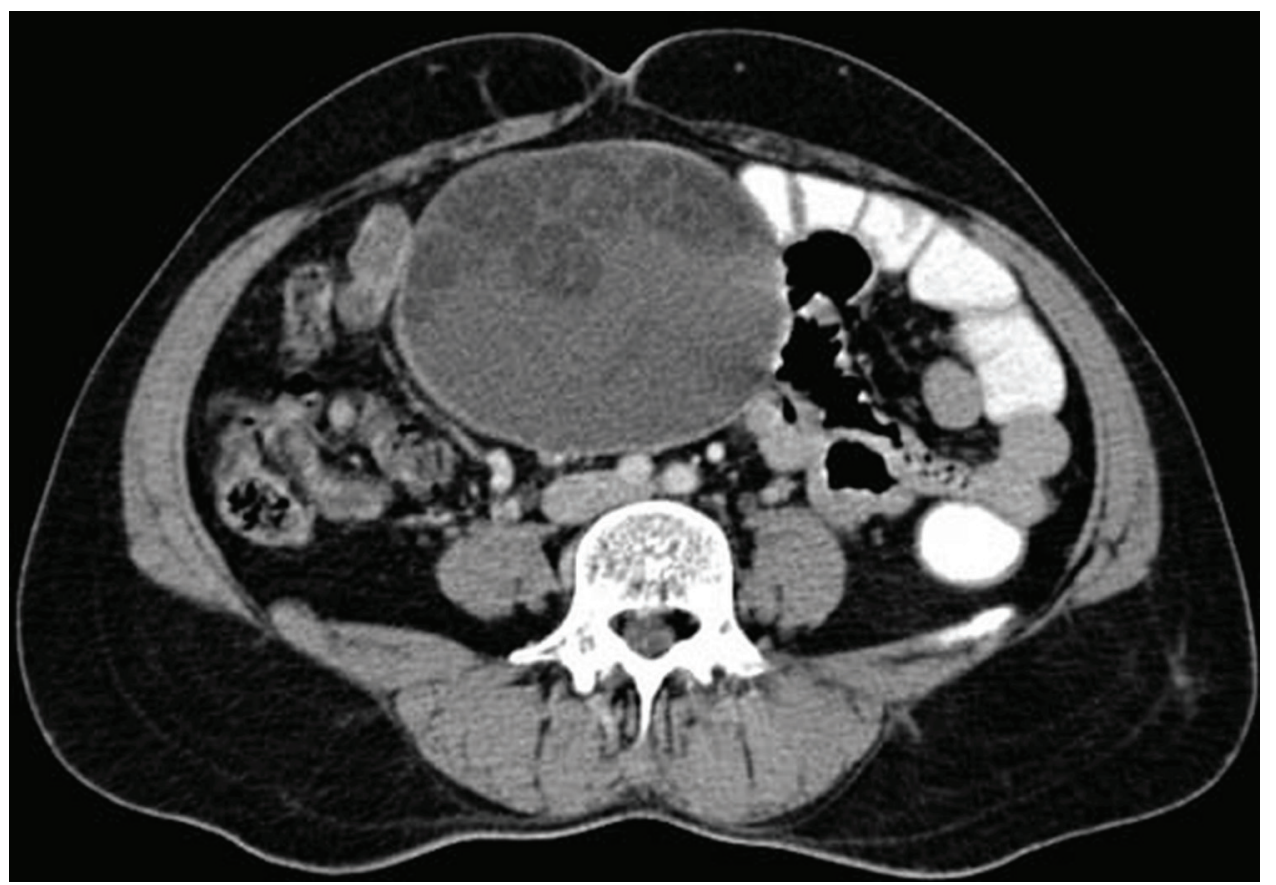

Figure 2 Axial CT image shows a thin-walled cyst with hypodense floating balls within.

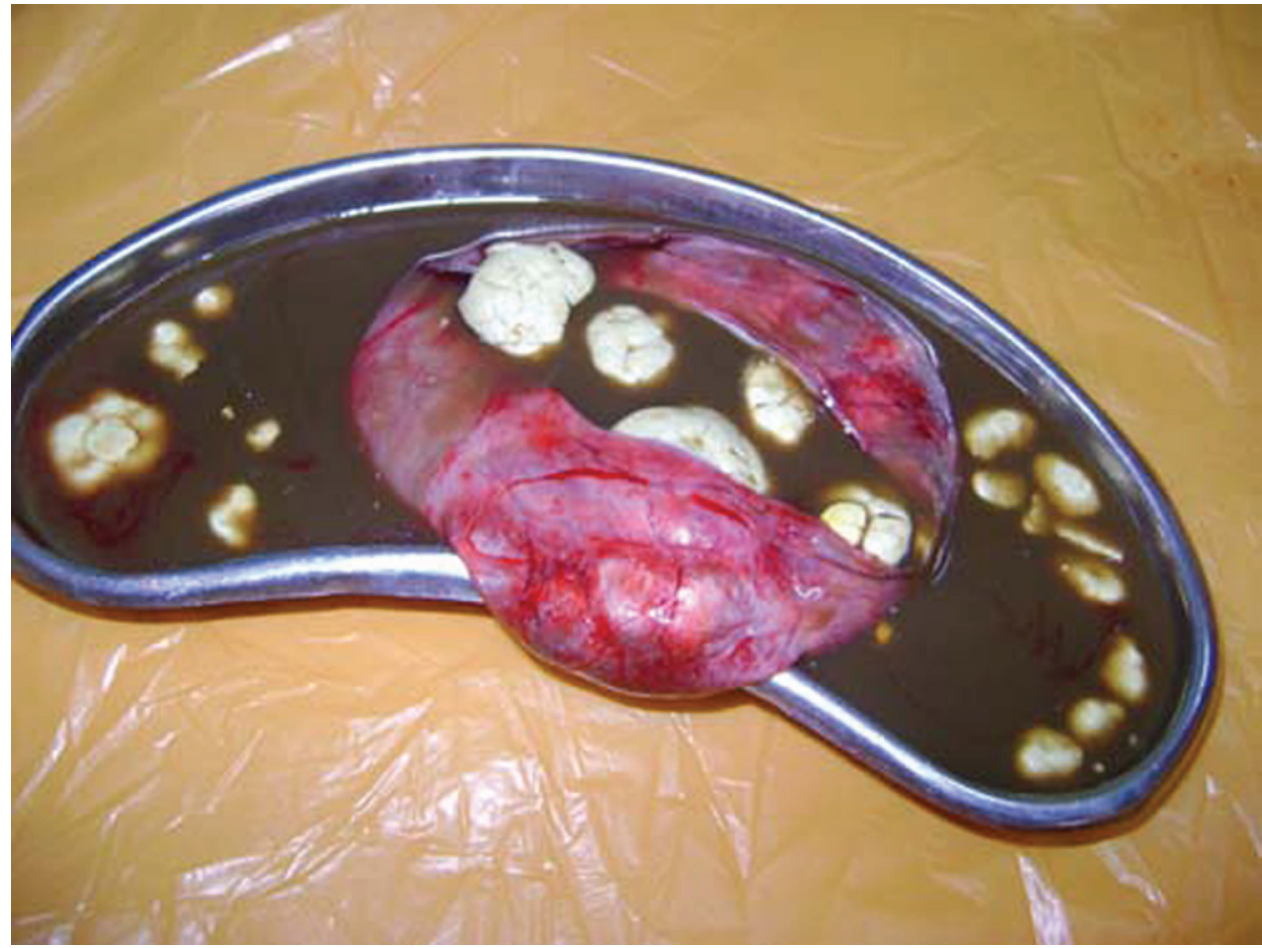

Figure 3 Gross specimen of the ovarian cyst showing multiple cheese-like sebum balls in serous fluid.

our knowledge, this appearance has not been reported in other tumours and is pathognomic for mature cystic teratoma.

Competing interests None.

Patient consent Obtained.

\section{REFERENCES}

1. Kawamoto S, Sato K, Matsumoto $\mathrm{H}$, et al. Multiple mobile spherules in mature cystic teratoma of the ovary. AJR Am J Roentgenol 2001;176:1455-7.

2. Jantarasaengaram S, Siricharoenthai $S$, Vairojanavong K. Cystic ovarian teratoma with intracystic fat balls. Ultrasound Obstet Gynecol 2003;22:102-3.

3. Tongsong $\mathbf{T}$, Wanapirak C, Khunamornpong $\mathrm{S}$, et al. Numerous intracystic floating balls as a sonographic feature of benign cystic teratoma: report of 5 cases. J Ultrasound Med 2006;25:1587-91. 


\section{BMJ Case Reports}

This pdf has been created automatically from the final edited text and images.

Copyright 2011 BMJ Publishing Group. All rights reserved. For permission to reuse any of this content visit http://group.bmj.com/group/rights-licensing/permissions.

BMJ Case Report Fellows may re-use this article for personal use and teaching without any further permission.

Please cite this article as follows (you will need to access the article online to obtain the date of publication).

Tandon A, Agarwal R, Tandon R, Prakash M. Multiple intracystic floating balls: an unusual but unique sonographic pattern of mature cystic teratoma. BMJ Case Reports 2011;10.1136/bcr.03.2011.3962, date of publication

Become a Fellow of BMJ Case Reports today and you can:

- Submit as many cases as you like

- Enjoy fast sympathetic peer review and rapid publication of accepted articles

- Access all the published articles

Re-use any of the published material for personal use and teaching without further permission

For information on Institutional Fellowships contact consortiasales@bmjgroup.com

Visit casereports.bmj.com for more articles like this and to become a Fellow 